\title{
Unacceptable Forms of Work in the Thai Sex and Entertainment Industry
}

\author{
Leo Bernardo Villar
}

\section{Abstract}

This article examines the working conditions in sex and entertainment work in Thailand using the Unacceptable Forms of Work (UFW) Framework. Criminalisation of sex work and insufficient oversight of labour conditions increase the vulnerability of sex workers to police harassment; prevent sex workers from accessing legal and social protections; and contribute to the decent work deficit in the sector. Protecting the human rights of sex workers and ensuring decent work in the Thai sex and entertainment industry necessarily involves the decriminalisation of sex work; amending labour and social protection laws, policies, and systems to be inclusive of sex workers; and ensuring implementation. Throughout the process of policy change, the involvement of sex workers, their employers, and civil society organisations is crucial.

Keywords: sex work, working conditions, unacceptable forms of work, Thailand

Suggested citation: L B Villar, 'Unacceptable Forms of Work in the Thai Sex and Entertainment Industry’, Anti-Trafficking Review, issue 12, 2019, pp. 108 126, www.antitraffickingreview.org

\section{Introduction}

Currently, most debates on sex work are linked to morality and traditional gender and sexual norms, rather than public health and human rights. The pervasive stigma against sex work has been shaped and is maintained by national legislation and policies that are informed by dominant cultural and religious norms, and has often been exacerbated by the conflation of sex work 
and trafficking. ${ }^{1}$ Despite legitimate concerns about the sexual exploitation of children, forced labour, and human trafficking, Thai laws that aim to prevent and punish such criminal acts are often discriminatorily enforced to penalise and harass sex workers and fail to achieve their goals of ensuring individuals are not exploited. ${ }^{2}$

In Thailand, migrant sex workers are often treated as victims of trafficking regardless of their decision to enter sex work. ${ }^{3}$ Pushed by international pressure-particularly by the US State Department's Trafficking in Persons Report (TIP Report) — to act against human trafficking, Thai police have used trafficking to justify raids on entertainment establishments to arrest and detain sex workers, either as criminals under the Penal Code (1956, amended 2003) and the Prevention and Suppression of Prostitution Act (1996), or as victims of trafficking under the Prevention and Suppression of Human Trafficking Act (2008, amended 2015). ${ }^{4}$ In this environment, migrant sex workers - many of whom do not wish to be 'rescued'-become more vulnerable to rights abuses. They may end up in poorer working conditions and situations where they have little leverage over their employers. ${ }^{5}$ Such misguided anti-trafficking responses compound the structural barriers to decent work that sex workers already face. While anti-trafficking raids are portrayed as 'rescue operations', for sex workers, raids regularly result in lost livelihoods, reduced access to support structures, and deportation back to situations of poverty. ${ }^{6}$

Article 6 of the Convention on the Elimination of All Forms of Discrimination against Women, 1979 (CEDAW) provides that 'States Parties shall take all appropriate measures, including legislation, to suppress all forms of traffic in women and exploitation of prostitution of women. ${ }^{7}$ Although this

1 EMPOWER, Moving Toward Decent Sex Work, EMPOWER University Press, Chiang Mai, 2016; EMPOWER, Sex Workers and the Thai Entertainment Industry, EMPOWER Foundation submission to the Committee on the Elimination of Discrimination Against Women, Sixty-seventh Session, 3-21 July 2017, retrieved 13 March 2018, http://www.nswp.org/resource/empower-thailand-cedawshadow-report; Global Alliance Against Traffic in Women, Sex Workers Organizing for Change: Self-representation, community mobilisation, and working conditions, GAATW, Bangkok, 2018.

2 EMPOWER, 2016.

3 EMPOWER, 2017.

4 EMPOWER, Hit \& Run: The impact of anti trafficking policy and practice on sex worker's human rights in Thailand, EMPOWER Foundation, Chiang Mai, 2012.

5 EMPOWER, 2012.

6 Ibid.; See also: Global Alliance Against Traffic in Women, Collateral Damage: The impact of anti-trafficking measures on human rights around the world, GAATW, Bangkok, 2007.

7 UN General Assembly, Convention on the Elimination of All Forms of Discrimination against Women, 18 December 1979, Article 6. 
terminology allows for a broad interpretation and implementation, ${ }^{8}$ CEDAW can serve as foundation for the promotion of the rights of women sex workers and their freedoms. In the combined sixth and seventh periodic reports of Thailand in 2017, the CEDAW Committee expressed their concerns over the exploitation of sex workers and presented Thailand with recommendations, including a review of the Prevention and Suppression of Prostitution Act with an aim to decriminalise women in sex work and to ensure the full application of labour laws in all legally operating entertainment enterprises. ${ }^{9}$ However, the Thai government has yet to act on the Committee's recommendations. ${ }^{10}$

This paper is based on the findings of a research conducted by an independent consultant engaged by the International Labour Organization (ILO). ${ }^{11}$ It draws on site surveys and interviews with 107 respondents including 73 women, men, and transgender sex workers; 24 employers of sex workers; seven public health officials; and three representatives of civil society organisations that work to support sex workers. ${ }^{12}$ Sex worker respondents included Thai nationals, migrants from neighbouring countries, and stateless members of ethnic minorities. Data collection was done in five locations: Bangkok, Chonburi (Pattaya), Chiang Mai, Sa Kaeo, and Udonthani from December 2014 to May 2015.

Building on this primary data and a desk review of relevant literature and national policies on sex work in Thailand, this paper identifies the lack of decent work conditions in the Thai sex and entertainment sector within the twelve Dimensions of the Unacceptable Forms of Work (UFW) Framework. ${ }^{13}$ The UFW Framework was developed to address labour issues in informal work sectors, ${ }^{14}$ especially where marginalised populations predominate_-including, but not only, sex work and domestic work. Therefore,

8 International Women's Rights Action Watch Asia Pacific and Global Network of Sex Work Projects, Framework on Rights of Sex Workers \& CEDAW, IWRAWAP, Kuala Lumpur, 2017.

9 Committee on the Elimination of Discrimination against Women, Concluding observations on the combined sixth and seventh periodic reports of Thailand, adopted by the Committee at its sixty-seventh session 3-21 July 2017, retrieved 14 August 2018, https://www.fidh.org/IMG/pdf/cedaw_c_tha_co_6-7_25136_e.pdf.

10 GAATW, 2018.

11 At the time of writing this paper, the study remains unpublished. I obtained access to the data in my role as a consultant with the ILO. Further information about the study can be requested from the ILO.

12 The identities of the respondents quoted in this paper have been anonymised to protect their safety and privacy. Sex worker respondents are identified by their gender and the kind of entertainment place in which they work.

13 J Fudge and D McCann (eds.), Unacceptable Forms of Work: A global and comparative study, International Labour Office, Geneva, 2015.

${ }^{14}$ Ibid., p. 48. 
it is important to note that the aim of this paper is not to identify sex work as an unacceptable form of work. Rather, it argues that indications of unacceptable forms of work and the increased vulnerability of sex workers to exploitation occur as a result of the criminalisation of sex work in Thailand and insufficient oversight of labour conditions. Addressing these issues in the sex and entertainment industry requires the decriminalisation of sex work and meaningful recognition of the human and labour rights of sex workers.

\section{The Sex and Entertainment Sector in Thailand}

Since the 1950s, Thailand has become well known for its sex and entertainment sector when American soldiers began to use parts of the country as a rest and recreation centre during the Viet Nam War. In the 1980s and 1990s, an increase in foreign investment boosted tourism in Thailand along with the entertainment sector. ${ }^{15}$ As a result of this expansion, many entertainment venues were established in major tourist destinations including Bangkok, Pattaya, Phuket, and Chiang Mai; this was followed by the influx of Thai and migrant entertainment workers. ${ }^{16}$ Sex workers are often legally employed as entertainers in venues, including karaoke bars, beer bars, a-go-go bars, and massage parlours ${ }^{17}$ where providing sexual services occurs supplementary to entertainment work. ${ }^{18}$ As one respondent said:

'It's a kind of supplementary work here. The bar doesn't force all employees to go with clients. It's just a karaoke bar here. The [sex] work sort of hides itself between the employee and the client.' Man sex worker, karaoke bar

Although many brothels have transformed into karaoke or beer bars, some brothels still exist in Thai-Lao border areas where many Lao migrant entertainment workers are found. ${ }^{19}$

While it may be surmised that the concentration of entertainment venues in major cities like Bangkok and Pattaya indicates a substantial international clientele for sex and entertainment workers, a larger segment of the

${ }^{15} \mathrm{~L}$ L Lim, The Sex Sector: The economic and social bases of prostitution in Southeast Asia, International Labour Office, Geneva, 1998, p. 214.

16 Ibid.; GAATW, 2018.

17 In Thailand, massage parlours are considered to be entertainment establishments under the Entertainment Places Act 1966, and are distinct from spas which are seen to provide health-related services.

18 ILO, unpublished

19 Ibid. 
entertainment sector serves local clients. ${ }^{20}$ According to Lim, there are several conditions within Thai society that support a high local demand for sex and entertainment services, including the social acceptance of men buying sexual services, the increased disposable income of middle- to upper-class Thais, and the development of intra-Thai tourism, which arguably tends to promote the sex sector. ${ }^{21}$

\section{The Unacceptable Forms of Work Framework}

The Unacceptable Forms of Work model provides a comprehensive framework for addressing 'non-standard' forms of employment, including casual and informal work. ${ }^{22}$ Since sex work is often situated outside the formal labour market-beyond the scope of the International Labour Standards — the UFW Framework serves as a model with which to identify and analyse unacceptability in the world of sex work. The UFW model contains twelve dimensions of unacceptability and indicators designed to be responsive to the socio-economic contexts of countries at different levels of development: forced labour; health and safety; income; security; working time; voice mechanisms; child labour; social protection; equality, human rights, and dignity; legal protection; family and community life; and work organisation. ${ }^{23}$

\section{The Twelve Dimensions of Unacceptability in the Thai Entertainment Sector}

\section{Forced labour}

Only three of the 73 sex worker respondents who work in entertainment places reported experiencing forced labour indicators. Two Thai women sex workers — one based in Bangkok, and another in a border province-mentioned a lack of freedom to exit work premises. A stateless sex worker based in Chiang Mai also mentioned being coerced into providing services to clients.

These isolated cases of coercion and lack of freedom of movement highlight the need to enhance and adapt the implementation of labour inspections in order to ensure that entertainment establishments abide by the regulations

20 P Guest, A Prohmmo, J Bryant, S Janyam, D Phuengsamran, Survey of Sexual and Reproductive Health of Sex Workers in Thailand, Institute for Population and Social Research, Mahidol University, Nakhon Pathom, 2007.

${ }^{21}$ Lim. See also: B Anderson and J O'Connell Davidson, Is Trafficking in Human Beings Demand-driven? A multi-country pilot study, IOM, Geneva, 2003, pp. 17-18.

22 ILO, 2015 p. 48.

23 Ibid. 
set forth in Thai labour laws. Aside from these cases, sex worker respondents did not report being deceived, coerced, or threatened to entertain clients. As one respondent stated:

'Going out with clients [is] up to us. If we want money, we can go with them, if not, then don't. No coercion.' - Woman sex worker, beer bar

\section{Health and safety}

For sex workers, the challenges to occupational safety and health $(\mathrm{OSH})$ are inherent in the physical nature of their work and compounded by unsafe workplaces and the lack of access to responsive services. Thus, a worker should ideally benefit from a national policy and programme on periodical reviews of occupational safety and health in working environments. ${ }^{24}$

Although the Entertainment Places Act (1966, amended 2003) requires entertainment venues to acquire operating licenses from local police, it does not offer meaningful health and safety protections to entertainment workers. ${ }^{25}$ Public health officials admit that the Ministry of Public Health's auditing units only focus on the structure and facilities of businesses, not the occupational safety and health of workers:

'[Auditing units] don't look at people [i.e., they only audit the physical environment of the workplace], and there aren't any sex workers reporting or filing complaints about work-related injuries. This is not within social security coverage. There are no complaints because they are invisible. Whatever problems they encounter don't get addressed and that's the end of it. If they go to the police, they would be asked [about their workplace] and get arrested, because what they do is against the law. The law does not provide for them.' - Public health official

As a result of this lack of oversight, many sex workers experience substandard working and living conditions. Most sex workers (60 out of 73) had OSHrelated complaints, including the lack of adequate toilets, dirty work environments, loud noises, lack of privacy in shared sleeping quarters, absence of smoke ventilators, fire exits, and escapes, and iron bar fixtures on doors and windows in some workplaces. Two respondents described conditions as follows:

${ }^{24}$ ILO, 2015, p. 85.

25 R Arora, 'Female Migration and Labor in Thailand: When law and society continue to exclude you', UCLA Journal of International Law \& Foreign Affairs, vol. 21, no. 1, 2017, pp. 70-97. 
'We do have separate toilet facilities [for employees], but there's only one. So sometimes we have to use the toilets for customers.' - Man sex worker, a-go-go bar

'I sleep on a sofa... No rooms. Just the place where we work.' Woman sex worker, massage parlour

Access to HIV prevention and treatment as well as sexual and reproductive healthcare is also vital to sex workers. The study found that sex workers are less willing to get tested and access treatment due to community-based clinics losing staff and services as a result of the centralisation of health services into provincial hospitals. Sex workers often feel uncomfortable seeking care in large state-run hospitals due to the high volume of patients, longer waiting times, and a generally less welcoming atmosphere. Healthcare providers may have biased perceptions against sex work and end up discriminating against them. Furthermore, police often use the possession of condoms as evidence against sex workers, ${ }^{26}$ thus discouraging them from using condoms and increasing their vulnerability to HIV infections. ${ }^{27}$

While Thai sex workers can more easily access health services through Thailand's universal health care system, which includes STI screening every three months, migrant workers who are not able to enrol in available health insurance schemes and whose employers do not provide these services are forced to visit private doctors or clinics. ${ }^{28}$ According to Barmania, many undocumented migrant sex workers, particularly in border areas, have to pay for HIV testing and treatment themselves. ${ }^{29}$ Therefore, discriminatory health systems, the lack of access to health information, and the lack of affordable healthcare discourage sex workers, including migrants, from seeking and accessing health services and contribute to the indications of UFW in the sector.

26 EMPOWER, 2016.

27 NSWP, The Impact of Criminalisation on Sex Workers' Vulnerability to HIV and Violence, Policy Brief, 2017, retrieved 3 January 2019, http://www.nswp.org/ resource/the-impact-criminalisation-sex-workers-vulnerability-hiv-and-violence.

28 S Barmania, 'Thailand's Migrant Sex Workers Struggle to Access Health Care', The Lancet, vol. 382, 2013, pp. 493-4, https://doi.org/10.1016/S01406736(13)61681-5.

29 Ibid. 


\section{Income}

Sex work often provides higher incomes than other job options generally available to migrants or women of lower socio-economic status. While income estimates vary across different sources, ${ }^{30}$ sex workers earn a monthly total income above the monthly minimum wage (approx. THB 10,000 or USD 300), due to additional income sources, including tips, drink shares, ${ }^{31}$ off fees, and bar fines. ${ }^{32}$ With this additional income added to their basic monthly salaries, sex workers can potentially earn a minimum total monthly income of THB 15,000 (approx. USD 450). Some sex workers can earn significantly more, up to THB 60,000 (approx. USD 1,800). ${ }^{33}$

The study found that, while sex workers may earn a total income above the minimum wage, there are no official standards on wage setting across different entertainment establishments. As a result, basic monthly salaries vary depending on venue. For instance, star dancers in Bangkok receive more than THB 10,000 in basic monthly salary, but other workers receive less.

The income sex workers earn is offset by the many unfair wage deductions imposed by employers and managers. These include, for example, if workers take additional days off or a sick leave, fail to undergo mandatory health checks, or do not take an 'off' client to a place designated by the establishment. These deductions can range from THB 100 to 2,000 depending on the penalty incurred. ${ }^{34}$ One respondent described the fines for lateness:

30 In the 1998 ILO report, the average monthly income of women sex workers was THB 20,000 (Lim, 1998, p. 153), while according to a 2017 interview with Liz Hilton of EMPOWER, sex workers can earn two to ten times the daily minimum wage (GAATW, 2018, p. 49).

31 Drink shares are an amount that workers get from what clients pay for drinks in the establishment.

32 Off fees are the payment that a sex worker directly receives from a client when outside their place of work. Going out with clients does not always involve sex. Some 'off' outings include just providing companionship as a friend, sleeping together without sex, or just going out for a walk. Bar fines are fees paid by the client to the employer in order to take a sex worker outside of the venue.

33 According to the public health officials interviewed for this study, migrant sex workers in the lower end establishments along the Thai-Lao border can earn as much as THB 50,000-60,000 per month if they have sex with up to ten clients per day.

34 Section 76 of the Labour Protection Act prohibits employers from making any deductions from basic pay, overtime pay, holiday pay, and holiday overtime pay except for payment of income tax, labour union contributions, debts the employee owes to savings cooperatives, and employee contributions with respect to the Employee Welfare Fund. See: Labour Protection Act, B.E. 2541 [1998], available at https://www.ilo.org/dyn/natlex/natlex4.detail?p_lang=en\&p_isn=49727. 
'If you come to work later than 7 p.m., it's a 100 baht fine, and if later than 8 p.m., it's a 500 baht [fine] for Monday through Thursday, and a 700 baht [fine] for Friday through Sunday.' - Man sex worker, massage parlour

\section{Security}

Job security in the UFW model includes indicators such as day labour, casual and zero-hour contracts, and termination of employment without valid reason or without procedural protections.

Few respondents had to submit a written job application, and none reported being given any formal employment contract. ${ }^{35}$ Employees of certain types of venues, in particular traditional massage parlours, reported that they had no discussion or agreement about going out with clients during hiring but could be expected to later on. In venues where no explicit agreements were made about providing sex services to clients, services were arranged either by the owner/manager discreetly within the establishment, or between the sex worker and the client without the owner/manager's involvement. Managers who have no direct involvement in transactions for sex services can deny this aspect of the business. In some bars, workers may be subject to zero-hour contracts where they are only expected to sell a minimum number of drinks but are not fully recognised as employees. Two respondents described the arrangements as follows:

'There was no [formal] agreement. It was voluntary. [When] you work in this kind of job, you know what you're getting into.' Woman sex worker, coyote bar

'No [formal] agreement with the employer. I had a rough idea of what [the work] would be, and I was willing to do it... but I didn't know all the details like the drink share, off fee, or pay deduction rate, and only found out later. But nothing I could do about it, so OK.' - Transgender sex worker, a-go-go bar

The lack of job security for many entertainment workers can be attributed to insufficient oversight of labour conditions. As a result, employment practices for entertainment workers are unregulated and labour inspections overlook and fail to protect them from unfair employment termination.

35 The terms of work (i.e. job description, wage, etc.) were either agreed upon verbally or not discussed at all. None of the respondents was asked to sign a contract. 


\section{Working time}

Excessive working hours, insufficient weekly and daily rest, lack of paid holiday leave, and night work are some of the common experiences of sex workers in terms of working time. Most venues where sex services are available have late operating hours, typically opening from early to late afternoon and closing from around midnight to 2 or 3 a.m. Sex workers did not report many complaints regarding working hours. The most common complaint was the insufficient number of days off as some had only two days a month off, and many had none.

In general, sex workers have no paid holiday leave ${ }^{36}$ and most establishments arbitrarily set an employee's weekly day off. Some allow workers to choose their own days off within certain restrictions and conditions; for example, they cannot have days off on weekends, or take consecutive days off. Taking more days off (including sick leave) ${ }^{37}$ than allowed usually incurs steep wage deductions. Workers in a-go-go and beer bars who have two to four days off a month are subject to higher wage deductions than workers in other venues if they take extra days off-up to THB 500-700 per day. In other venues, sex workers may have up to one day off per week, subject to wage deductions of THB 300-500 for each additional day. In venues that do not allow any free days, employees pay penalties that could range between THB 100 and 1,000 per day. ${ }^{38}$ One respondent described the deductions as follows:

'Taking Friday and Saturday off is not allowed, nor during the $25^{\text {th }}$ and the $5^{\text {th }}$ days of the month. If you take a day off [during that time], the deduction is 700-1,000 baht. And if that day is a Friday or Saturday and the last or first day of the month, the rate is 1,000 baht. If you come late to work, it's 2 baht per minute, and if you go out with a customer [during regular working hours], it's 400 baht.' Woman sex worker, karaoke bar

36 Section 30 of the Labour Protection Act states that an employee who has worked continuously for one year shall be entitled to an annual holiday of not less than six working days. Section 56 states that employers shall pay an employee their basic pay equal to the basic pay of a working day during (1) weekly holidays, except for employees who receive wages calculated on a daily, hourly, or piece rate basis; (2) traditional holidays; and (3) annual holidays. See: Labour Protection Act, B.E. 2541 [1998].

${ }^{37}$ Section 57 states that employers shall pay an employee their basic pay during a sick leave equal to the basic pay of a working day for the duration of the sick leave, but not exceeding 30 working days per year. Ibid.

${ }^{38}$ Section 28 states that employees are entitled to at least one day off per week as a weekly holiday and the interval between each weekly holiday shall be no longer than six days. An employer and employee may agree in advance to fix which day will be the weekly holiday. Ibid. 
As such, many sex worker respondents desired a weekly day off without wage deductions to be a regular part of their work.

Women continue to suffer from unfair treatment and wage discrimination even in sex work. Women and transgender sex workers across all venues face stricter rules and are often subject to wage deductions for additional days off. Most men sex workers, however, were allowed up to four or five days off per month and fewer were subject to wage deductions for taking additional days off (and when deductions were charged it was often at a lower rate).

While excessive hours and lack of sufficient days off may amount to a forced labour offence, determining whether overtime is indicative of forced labour can be complex. ${ }^{39}$ Regardless, the working hours of sex workers highlight the need for the Thai government to improve comprehensive oversight and implementation of labour laws in entertainment venues, especially to ensure access to days off and sick leave without wage deductions.

\section{Representation and voice mechanisms}

Sex workers in Thailand currently do not have a form of workers' organisation or association. There is no legislation that officially restricts sex workers from unionising and at least one sex worker group has explored the possibility of becoming part of a union. ${ }^{40}$ The Labour Relations Act (1975, amended 2001) limits the ability of migrant workers to participate in unions. ${ }^{41}$

The criminalisation of sex work and the stigma surrounding it create an environment where sex workers' voices are gravely unrepresented in decisionmaking processes throughout the chain of governance-from legislation, national and sub-national policies, and implementation that affect sex workers. Nevertheless, some sex workers have joined the activities of or have become a member of an NGO supporting sex workers such as EMPOWER, SWING, Sisters, or Mplus. ${ }^{42}$

39 ILO, 2012.

40 Interview with Liz Hilton from EMPOWER.

${ }^{41}$ Labour Relations Act (1975, amended 2001), Section 101(2).

42 EMPOWER is an organisation in Chiang Mai by and for women sex workers that provides lessons on literacy, foreign languages, and other skills that sex workers choose to learn. It also manages the Can Do Bar, which is the organisation's model entertainment venue for safe and fair sex work. SWING, or Service Workers in Group, works with sex workers of all genders and nationalities. It provides a variety of health services to sex workers through three peer-led dropin centres based in tourist spots. Sisters Foundation is a transgender rights organisation in Pattaya. It provides health services to transgender sex workers and works closely with local police to end police violence against transgender women. MPlus is an organisation in Chiang Mai that provides HIV prevention, treatment, and care services to men who have sex with men, and men and transgender sex workers. It advocates for HIV awareness and an end to discrimination against people living with HIV and sex workers. 


\section{Child labour}

None of the respondents in the study was underage, but a few sex workers said they started with sex work before the age of 18. Public health officials and sex worker organisation respondents stated that young sex workers are less common than they used to be due to the strict laws against child labour and sexual exploitation of children in Thailand.

However, there is anecdotal evidence of teenagers or secondary school students seeking customers in public areas (often parks) and/or through online chat forums and social media. Female vocational school and college students (who may or may not be older than 18) working on a freelance basis through establishments, such as karaoke bars, massage parlours, and beauty salons, were also mentioned. Schoolboys have also been said to advertise and communicate online with clients for sex in internet shops.

Despite some young people below the age of 18 providing sexual services with or without knowledge of the health and safety risks that come with sex work, there is often more to these cases than the sexual exploitation of children. Poverty, lack of access to education, and general lack of opportunities for social and economic mobility are among the factors that lead young people into sex work. NGO respondents said that many young people in sex work have experienced domestic violence, school bullying, child abuse, and sexual abuse from their peers and family members prior to doing sex work. ${ }^{43}$

Whether these young people work on their own or have older persons serve as intermediaries, Thai law prohibits procuring sex with minors. In cases where sex worker organisations encounter young sex workers, these children are given counselling on the health and safety risks of sex work and are referred to child protection organisations. ${ }^{44}$

\section{Social protection}

Thai sex workers are not explicitly excluded from social protection laws but they are often deterred from accessing social security by fears of facing arrest, public shaming, and deportation. ${ }^{45}$ These deterrents, and more broadly the criminalisation of sex work and insufficient oversight of labour conditions, prevent sex workers from reporting employer non-compliance with social protection laws, as well as limit them from accessing benefits, including pensions and insurance. Sex workers who are not formally employed cannot enrol in social security schemes. Only managers, cashiers, and the few who

\footnotetext{
${ }^{43}$ ILO, unpublished.

${ }^{44}$ Ibid.

${ }^{45}$ EMPOWER, 2016.
} 
have employee status (as entertainment workers) are enrolled in the Thai social security programme, but often shoulder both employee and employer's contributions. ${ }^{46}$

Stateless and migrant sex workers, especially those with irregular status, are often unable to access social security mechanisms that regular migrants in formal job sectors have. Though health insurance coverage has been extended to migrant workers since 2001, barriers, such as requiring migrants to pay large fees and limited translation of information regarding benefits, severely limit migrants from fully enjoying their health insurance. ${ }^{47}$ Migrant sex workers, on the other hand, are unable to enrol in the health insurance scheme since sex work is not recognised as legitimate employment.

\section{Equality, human rights, and dignity}

Despite perceived tolerance of sex work in Thai society, sex workers of all genders continue to face deep societal stigma. For example, media reports about sex workers are often stereotypical and derogatory, portraying them as potential criminals and carriers of disease, particularly of HIV. ${ }^{48}$ The Thai media has routinely published reports using sensationalised photos and headlines that state the number of women rescued in raids. ${ }^{49}$

Transgender sex workers experience compounded stigma and discrimination. Transgender women are often portrayed negatively as sex workers and petty criminals. ${ }^{50}$ There are reports of transgender women (not always sex workers) facing random drug tests and arbitrary arrests for presumption of sex work while walking in shopping malls or on the streets in Pattaya. ${ }^{51}$ Many transgender sex workers feel bad about contributing to the continued association of transgender identity with sex work, which has negatively affected the community. ${ }^{52}$ Moreover, stigma affects the work of transgender sex workers, too:

46 ILO, unpublished.

${ }^{47}$ International Organization for Migration and World Health Organization, Financing Healthcare for Migrants: A case study from Thailand, IOM and WHO, Bangkok, 2009; V Tangcharoensathien, A A Thwin and W Patcharanarumol, 'Implementing Health Insurance for Migrants, Thailand', Bulletin of the World Health Organization 2017, vol. 95, 2017, pp. 146-151, http://dx.doi.org/10.2471/BLT.16.179606.

48 EMPOWER, 2017; GAATW, 2018.

49 EMPOWER, 2016.

${ }^{50}$ A Quan (ed.), A Tool for Change: Working with the media on sexual orientation, gender identity, expression, and sex characteristics in Thailand, Burapha University, Saen Suk, 2017.

51 C Yangharoenchai, 'Law cops out on transgender rights in Pattaya', Bangkok Post, 20 August 2017, retrieved 13 March 2018, https://www.bangkokpost.com/ news/special-reports/1309607/law-cops-out-on-transgender-rights.

52 L B Villar, Sisters, Boyfriends, and the Big City: Trans entertainers and sex workers in globalized Thailand, Master's Thesis, Chulalongkorn University, Bangkok, 2017. 
'[The client] knew that I was transgender. [He was taking me 'off'] and I was going with him, but it seemed a woman was jealous. She ran to tell him that I was kathoey. ${ }^{53}$ So the guy was embarrassed; so he pushed me away.' - Transgender sex worker, general bar

The study also found that workers may lose their jobs if found to be HIV positive or pregnant, which disregards ILO recommendations No. $200^{54}$ and $183^{55}$ respectively. Discrimination against people living with HIV is also prevalent in sex work since sex workers are one of the groups that bear the brunt of stigma against HIV. ${ }^{56}$

Stateless ethnic minorities and migrants are also subject to discrimination and exploitation in their working life. ${ }^{57}$ Due to a range of barriers including the criminalisation of sex work and the high costs associated with regular migration, migrant workers rely on brokers/intermediaries, which increases their risk of exploitation, harassment, and abuse by their employers, clients, and law enforcement officials. ${ }^{58}$

Sex workers of all genders experience various forms of abuse, violence, and harassment from clients. For example, two respondents noted:

'You can protect yourself to a degree, but sometimes you can't keep yourself safe. So you just have to do it, because if you don't you get hurt. Sometimes you see what clients are doing, and even you know that is illegal, you have to stay put.' - Transgender sex worker, coyote bar

'I called out to my friends. Called out to the cleaning woman that he was going to do something to me, and I was able to get out.' Woman sex worker, massage parlour

53 Kathoey, commonly translated as 'ladyboy' in English, refers to transgender women.

54 ILO, HIV and AIDS Recommendation, 2010 (No.200), 17 June 2010, Article 11.

55 ILO, Maternity Protection Convention, 2000 (No.183), 15 June 2000, Article 8.

56 National AIDS Committee, Thailand AIDS Response Progress Report, NAC, Bangkok, 2015.

${ }^{57}$ B Harkins and A Ali, 'Evidences or Attitudes? Assessing the foundations of Thailand's labour migration policies', Paper presented at the International Seminar on Mixed Migration in Southeast and East Asia, Bangkok, 2017.

${ }^{58}$ C B N Chin, Cosmopolitan Sex Workers: Women and migration in a Global City, Oxford University Press, Oxford, 2013; R S Parreñas, Illicit Flirtations: Labor, migration, and sex trafficking in Tokyo, Stanford University Press, Palo Alto, 2011. See also: B Harkins, 'Social Protection for Migrant Workers in Thailand' and C Natali, E Mcdougall and S Stubbington, 'International Migration Policy in Thailand', in J W Huguet (ed.), Thailand Migration Report 2014, United Nations Thematic Working Group on Migration in Thailand, Bangkok, 2014. 
Compounding these experiences are violence at the hands of police and other law enforcement officials and the military, ranging from frequent violent raids and random drug tests, to arbitrary arrests, extortion, and demands for bribes or protection money. ${ }^{59}$ Therefore, sex workers do not report their experiences of violence from clients to law enforcement, or even less life-threatening crimes, including being robbed or mugged by local gangs. ${ }^{60}$

\section{Legal protection}

Sex workers are unable to formally access legal protection. ${ }^{61}$ Despite some sex workers being legally employed as entertainers, many of them, including migrants, are deterred from reporting exploitative conditions and accessing legal protection due to the criminalisation of sex work:

'Are we safe? Well, I'm at risk of [being arrested by] police. I'm a foreigner here, not a Thai national. I don't have a work permit. I have to be alert. If there are cops around, then I go somewhere else.' - Transgender sex worker, general bar

Instead of protecting workers, labour inspection systems that should identify abuses in work conditions and terms of employment are often used to arrest sex workers. ${ }^{62}$ This is especially concerning for migrant sex workers who enter Thailand through irregular channels and are often misidentified as victims of trafficking. Despite provisions that afford many migrant workers in other sectors legal status, freedom to travel, and more opportunities, these processes are not available to most migrant sex workers ${ }^{63}$ who do not maintain a 'legitimate' job with an employer willing to support their application:

'If [sex workers] come in legally, I don't think there will be many problems, but when they come in illegally, they are definitely vulnerable... Many [violations], like safety issues, food. Whatever is given to them by the owner, that's all they will have to eat.' - Public health official

'The situation now ${ }^{64}$ is that migrants are seen as illegal. So when they work in sex work, they are [seen as] doubly illegal [from the perspective] of human trafficking and foreign migrant labour. This

59 EMPOWER, 2012.

6) EMPOWER, 2016.

${ }^{61}$ Arora, 2017; EMPOWER, 2016; EMPOWER, 2017.

${ }^{62}$ EMPOWER, 2012, 2016, and 2017.

${ }_{63}$ B Harkins, D Lindgren, and T Suravoranon (eds.), Risks and Rewards: Outcomes of labour migration in South-East Asia, International Labour Organization and International Organization for Migration, 2017.

${ }^{64}$ This refers to 2014 to 2015 when the interviews were conducted. 
means whenever a migrant is found in sex work, he or she is automatically considered a human trafficking victim, while in fact, s/ he may work voluntarily. As long as foreign migrants working in Thailand are considered illegal, they will have to hide [from authorities] and this puts them at a disadvantage and the employers have an advantage.' - Director, NGO

Inadequate regulation of labour practices and lack of accessible information on legal rights also increase the risk of sex workers to exploitative work conditions and prevent them from reporting labour law violations.

\section{Family and community life}

Instead of having paid maternity leave, sex workers who become pregnant are likely to have their employment terminated. Although remedies, such as being placed in a cashier position, exist in some establishments, they are rare. According to EMPOWER Foundation, 80 per cent of women sex workers are also mothers who provide and care for their children. ${ }^{65}$ Similar to previous sections, the inaccessibility of maternity protection for women sex workers points to the lack of oversight of basic labour rights.

Sex workers in the study did not feel that sex work impacted their life or their family in significant ways. Many said they would continue to engage in sex work until they had enough savings to set up a business, they or their children finished their education, or until they had a chance to go abroad. This illustrates how many sex workers see their work as a means to attain a better personal, family, and community life_f far from the narrative of sex workers being victims of trafficking and exploitation.

However, the misidentification of sex workers as victims of trafficking by anti-trafficking law enforcement has a detrimental effect on their families. ${ }^{6}$ Migrant sex workers and their families are often the most affected by antitrafficking raids, as migrants are more likely to be presumed to be trafficked and are often unaware of their rights and do not understand the purpose of interviews conducted by police. ${ }^{67}$ In these 'rescue operations', even migrant sex workers who appear over 18 and can produce identification documents are charged under the Prostitution Act, the Immigration Act, or the Alien Employment Act. Those who are unable to provide proof of age are disbelieved. ${ }^{68}$

${ }_{65}$ EMPOWER Foundation, S Okeyre and L Hilton, "When is sex work "decent work"?', Open Democracy, 9 April 2018, retrieved 20 April 2019, https:// www.opendemocracy.net/beyondslavery/empower-foundation-sam-okyere-lizhilton/what-would-make-sex-work-decent-work.

6o EMPOWER, 2017; GAATW, 2018.

${ }^{67}$ EMPOWER, 2016.

a EMPOWER, 2012. 
Being identified as a victim of trafficking often results in deportation. Lengthy legal processes prior to deportation take their toll on detained migrant workers. These individuals are likely to return home without money and are possibly still in debt from using brokers to facilitate their initial migration. As a result, they often return to work in Thailand or another country, including in sex work. ${ }^{69}$

\section{Work organisation}

Lack of influence over working hours and processes, excessive workloads, and intense physical and mental demands were less important concerns for sex worker respondents. However, meeting monthly drink and 'off' quotas to avoid wage deductions often put intense pressure on sex workers. Many entertainment venues set a quota for the number of customers that employees must go out with each month. In both Bangkok and Pattaya, employees who failed to meet the quota were punished by a THB 1,000 (approx. USD 30) wage deduction. However, some bars allow substitution between drink quotas and 'off' quotas:

'Most bar hostesses have a 7,000-baht monthly salary, and [have to] make about 80 drinks or eight off deals. If you don't get 'off' deals, you can substitute 15 drinks per one off.' - Woman sex worker, beer bar

Many sex workers said they had regular customers who help them fill the minimum 'off' quota:

'I have regular customers and won't go out with just anybody. Each of us has our own patrons, and not just gay [clients]. They are women, men, gay men, kathoeys.' - Man sex worker, beer bar

Regardless, abusive experiences with some clients take a toll on sex workers' physical and mental well-being, which underscores the importance of sufficient rest days and mental health support for sex workers.

69 GAATW, 2007. 


\section{Conclusion}

Looking at the Thai sex and entertainment sector through the lens of the twelve dimensions of the UFW Framework, this paper has attempted to present signposts that alert us to the indicators of unacceptable forms of work, including forced labour, in the sex industry that need to be addressed. These signposts are often interrelated and need to be addressed as such. For example, the societal discrimination and negative media portrayal of sex workers (under equality, human rights, and dignity) is inextricably linked to the lack of access to legal protection, health services, and social security; the lack of representation and voice mechanisms intersect with the inability of sex workers to claim social security benefits, have maternity leave, have sufficient days off, protect themselves from unfair employment termination, have adequate working and living conditions, and so on.

Crossing the different themes in this paper have been the impact of criminalisation and the need to improve comprehensive and effective oversight of labour laws in the Thai sex and entertainment sector. Criminalisation of sex work and insufficient oversight have enabled the expansion of unsafe and unfair working environments that increase the risk of sex workers-especially migrants - to exploitation, forced labour, and other human rights abuses. Migrants often risk more by engaging in sex work than their Thai counterparts, as they face not only police arrests and abuse from clients and employers, but also misidentification as victims of trafficking, deportation, loss of income and livelihood, etc.

In this context, the decriminalisation of sex work-which would involve updating labour laws and policies to definitively include sex workers into labour and social protection mechanisms, and increasing sex workers' access to free or affordable health care systems - is a crucial first step to protect the human rights of sex workers. In addition to these policy changes, government oversight must be better equipped at identifying and addressing the specific labour rights issues of sex workers, including migrants. Improving oversight of labour laws would require ensuring that labour and health inspection systems listen to, record, and address sex workers' complaints, including those of hostesses, entertainers, and massage workers.

With the aim of supporting sex workers' voices within policy and human rights discussions, this paper presented the different labour and human rights issues that women, men, and transgender sex workers in Thailand face in the context of criminalisation. Listening to these voices elucidates the reality of sex workers and the indicators of unacceptable forms of work in the entertainment and sex industry. This paper challenges the common myths and misconceptions regarding sex work, often tied to the moral and gender politics that also influence many anti-trafficking interventions. As the lived 
experiences of sex workers differ from dominant portrayals of sex work as inextricably linked to trafficking, the lack of decent work conditions in the sex sector, as a result of criminalisation and insufficient oversight of labour laws, highlights a crucial labour issue that bears addressing.

Leo Bernardo Villar is a consultant with the International Labour Organization in Bangkok, Thailand. He has worked on issues related to the human rights of women, LGBTI people, youth, people living with HIV/ AIDS, migrant workers, and sex workers. He holds a Master's degree in International Development Studies from Chulalongkorn University and has recently completed his Master's thesis on the experiences of trans entertainers and sex workers in Bangkok and Pattaya. Email: oel.villar@gmail.com 